\title{
Education and training
}

\section{The impact of training on outcomes in primary vascular access surgery}

\author{
AR Weale, J Barwell, H Chant, PA Lear, DC Mitchell \\ Department of Vascular and Transplant Surgery, Southmead Hospital, North Bristol NHS Trust, Westbury on Trym, \\ Bristol, UK
}

\begin{abstract}
Background: There is evidence that the outcome of arteriovenous fistula surgery is dependent on the surgeon performing the operation. Vascular access surgery provides excellent technical training for surgical trainees. The effect of surgical trainees on the outcome of fistulas was evaluated.

Methods: The grade of the main operator for all first attempted (primary) upper limb arteriovenous fistulas, between February 1998 and August 2001, was identified. Median follow-up was 18.0 months (IQR, 6.5-30.1 months). Successful use of fistula for dialysis, fistula patency and survival were assessed.

Results: 441 primary fistulas were formed in the study period. Median age was 67.5 years (IQR, $54.0-75.2$ years). $71 \%$ of all fistulas were formed at the wrist. Trainees performed $31.1 \%$ of all operations. The two groups (trainees and consultants) were well matched for age, sex, diabetes, and fistula type. Only $70.5 \%$ of patients proceeded to long-term haemodialysis. There were no significant differences in the successful use of AVF for dialysis or patency rates between the two groups. One and two year fistula survival in this group was $87.7 \%$ and $78.3 \%$ for trainees and $80.8 \%$ and $\mathbf{7 1 . 1} \%$ for consultants $(P=\mathbf{0 . 2 8 8} \log$ rank).

Conclusions: Surgical trainees can perform primary AVF surgery without significantly reducing fistula outcomes. Vascular access surgery can be utilised as a training operation.
\end{abstract}

Key words: Vascular access surgery - Training - Arteriovenous fistulas

$T^{1}$ The first choice for long-term haemodialysis access in Europe is the autogenous arteriovenous fistula (AVF). ${ }^{1}$ Maturation and patency rates remain disappointingly low in some series. Both the method of reporting ${ }^{2}$ and rates of patency of AVF vary considerably in the literature. Early or technical failure varies from $18 \%$ to $66 \%,{ }^{3-5}$ and reported primary patency at one year is $34-83 \%{ }^{5-8}$ Whilst $80 \%$ of patients in Europe currently dialyse with a fistula, only $24 \%$ of patients do so in US. ${ }^{1}$ The increased use of prosthetic vascular access grafts in the US is often attributed to poor early results for AVFs. ${ }^{6,9}$ However, vascular access grafts are associated with higher complication and intervention rates. ${ }^{10}$ Indeed, morbidity associated with all types of vascular access is estimated to account for $20 \%$ of hospital stays in patients with chronic renal failure. ${ }^{11}$ Providing the optimal site and type of vascular access is crucial to reduce patient morbidity and mortality.

Vascular access surgery provides excellent training opportunities for surgical trainees. ${ }^{12}$ It has been suggested, however, that the outcome of AVF is dependent mainly on

Correspondence to: Mr AR Weale, Department of Surgery, Southmead Hospital, Westbury on Trym, Bristol BS10 5NB, UK Tel: +44 (0) 117959 5166; Fax: +44 (0) 117959 5168; E-mail: andy@weale.org.uk 
the surgeon performing the operation. ${ }^{8}$ A recent study has also suggested that surgical trainees do not possess the necessary skills to perform AVF operations in all comers and, as such, place prosthetic grafts in preference. ${ }^{1}$ However, no study to date has examined the impact of surgical trainees on AVF outcome.

The aim of our study was, therefore, to examine the effect of supervised surgery, performed by trainees on successful use of AVFs and the subsequent fistula survival in a single institution.

\section{Patients and Methods}

\section{Patients}

All patients undergoing the first attempted (primary) autogenous wrist (radio-cephalic direct wrist access and posterior radial branch-cephalic direct access) ${ }^{2}$ and antecubital (brachial-cephalic upper arm direct access) ${ }^{2}$ fistulas between February 1998 and August 2001 were included in the study. Cases were identified using the hospital's computerised renal patient records and cross checked with theatre records. Patients' age, diabetic status and previous use of a temporary central venous line for haemodialysis were also recorded.

\section{Operations}

A consultant surgeon made the pre-operative assessment. The philosophy of the surgical unit was to place the first fistula preferentially in the non-dominant arm and in the most distal position that appeared clinically feasible. Pre-operative duplex ultrasonography was not used to plan optimal fistula positioning or identify favourable training cases during this study. Fistulas were created using an end of vein to side of artery anastomosis with continuous $6 / 0$ synthetic monofilament. Operations were carried out under local anaesthetic as a preference; however, a number of cases were performed under general anaesthesia due to patient wishes. The type of anaesthetic was, therefore, identified for each case. No anticoagulation was used routinely. Four consultant surgeons performed or supervised the operations. During the period studied, 6 basic surgical trainees and 4 specialist registrars also performed AVF surgery. It was not possible to determine the degree of consultant supervision in this retrospective series (scrubbed or unscrubbed) accurately; however, consultants were present for all operations. The main operator for each case was identified using trainee log books and operation notes from patient records. No objective method of case selection for training was employed in this study. Patients were selected for trainees by the consultant on an ad hoc basis, depending on the consultant's evaluation of the trainee's ability at that time.

\section{Outcome}

The computerised renal patient records were accessed in October 2002 to identify the outcome of each fistula. Incomplete data were retrieved using written patient records. Median follow- up was 18.0 months (IQR, 6.5-30.1 months). A successful fistula was defined as a fistula that had been successfully used for dialysis. Presence or absence of a thrill was not used to define technical success, as the simple presence of a thrill does not determine whether a fistula will mature to become usable or can be used for dialysis. ${ }^{13}$ Postoperative duplex assessment of fistulas was not performed routinely and, as such, flow measurements were not uniformly available.

Fistula survival was defined as the proportion of the successful fistulas that had continued to work without intervention at 1 and 2 years. ${ }^{1}$ Primary functional patency was defined as the percentage of all fistulas attempted that were still being used for dialysis that had not required any intervention designed to maintain or re-establish patency at 1 and 2 years. ${ }^{2}$ Interventions included angioplasty, thrombectomy, and surgical revision of the fistula. Secondary functional patency was defined as the percentage of all the AVF attempted that were being used irrespective of interventions at 1 and 2 years. The time to first use, and the dates of death or transplantation were recorded as relevant. Patients who were transplanted, died or who never proceeded to long-term haemodialysis were considered as lost to follow-up and were censored for all survival analysis.

\section{Statistical analysis}

Patient demographic factors were compared using MannWhitney U-test for continuous variables and Chi-squared for categorical values. For fistula success, proportions were compared using a Chi-squared test. Patency and fistula survival was analysed using life tables and KaplanMeier survival analysis. The two groups were compared using a log rank test. Statistical analysis was performed with the Software Package for the Social Sciences (version 10.1 for Windows, SPSS Inc., Chicago, IL, USA). A $P$ value of $<0.05$ was considered statistically significant.

\section{Results}

We identified a total of 441 patients who underwent their first AVF operation in the 42-month study period. It was not possible to identify the main operator for 3 patients. A total of $136(31.1 \%)$ operations were performed by trainees. The demographics of both groups are shown in Table 1. Patients were well matched for age, sex, diabetes, type of fistula, anaesthetic and prior use of temporary central venous line (CVL) for dialysis. 


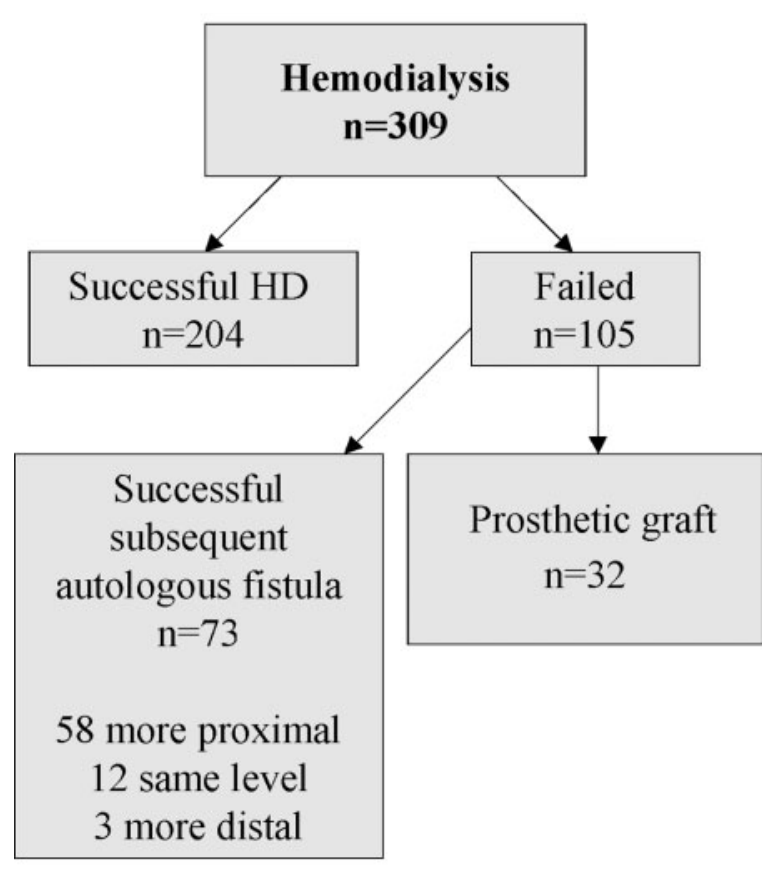

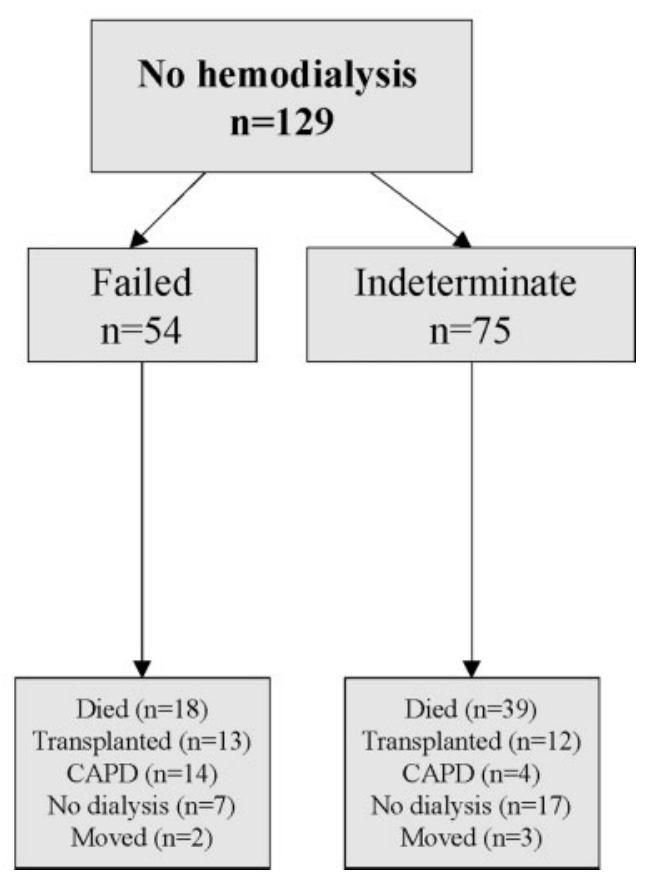

Figure 1 Patient outcome.

The outcome of patients following fistula formation is shown in the flow chart (Fig. 1).

The outcome of the primary AVF operation was indeterminate for 75 of the 438 patients in the study. Of the 75 , 39 died, 12 were transplanted, 21 never proceeded to longterm haemodialysis and 3 moved hospital prior to assessment of maturation of the fistula. One-third $(n=26)$ of this group of patients had fistula operations performed by trainees. These patients were censored at day 0 for all Kaplan-Meier survival analysis. Of the 363 remaining patients, only 55.6\% (204) successfully used the primary AVF for dialysis. The proportion of fistulas that were successful and unsuccessful is shown in Table 2 . There is no significant difference between trainees and consultants.

Overall primary functional patency was $54.1 \%$ at 1 year and $47.5 \%$ at 2 years. There was no difference in primary functional patency between fistulas formed by trainees and consultants $(P=0.712 \log$ rank). This is

Table 1 Patient demographics

\begin{tabular}{llll}
\hline & Trainee & Consultant & $P$ value \\
\hline Number & 136 & 302 & $\mathrm{n} / \mathrm{a}$ \\
Median age & 67.2 years & 67.9 years & $0.781^{*}$ \\
IQR & $55.6-74.3$ years & $50.6-75.9$ years & $0.658^{+}$ \\
Female sex & $53(39.0 \%)$ & $111(36.8 \%)$ & $0.279^{+}$ \\
Diabetic patients & $24(17.6 \%)$ & $67(22 .)^{\circ}$ & $0.192^{+}$ \\
Wrist AVF & $102(75.0 \%)$ & $208(68.9 \%)$ & $0.555^{+}$ \\
Local anaesthetic & $122(89.7 \%)$ & $118(39.1 \%)$ & $0.320^{+}$ \\
Use of CVL to dialyse prior to AVF & $60(44.1 \%)$ & & \\
\hline
\end{tabular}

Numbers in parentheses are percentages. IQR, inter-quartile range; $\mathrm{CVL}$, central venous line. ${ }^{*}$ Mann-Whitney $\mathrm{U}$ test. ${ }^{+} \mathrm{Chi}$-squared test.

Table 2 Documented successes and failures

\begin{tabular}{lccccc}
\hline & \multicolumn{2}{c}{ Trainee (AVFs: $n=110)$} & \multicolumn{2}{c}{ Consultant (AVFs: $n=253)$} & $P$ value \\
& Successful & Unsuccessful & Successful & Unsuccessful & (Chi squared) \\
\hline AVF (all) & 58 & 52 & 146 & 107 & 0.379 \\
Wrist AVF & 42 & 40 & 98 & 78 & 0.503 \\
Antecubital AVF & 16 & 12 & 48 & 29 & 0.629 \\
\hline
\end{tabular}




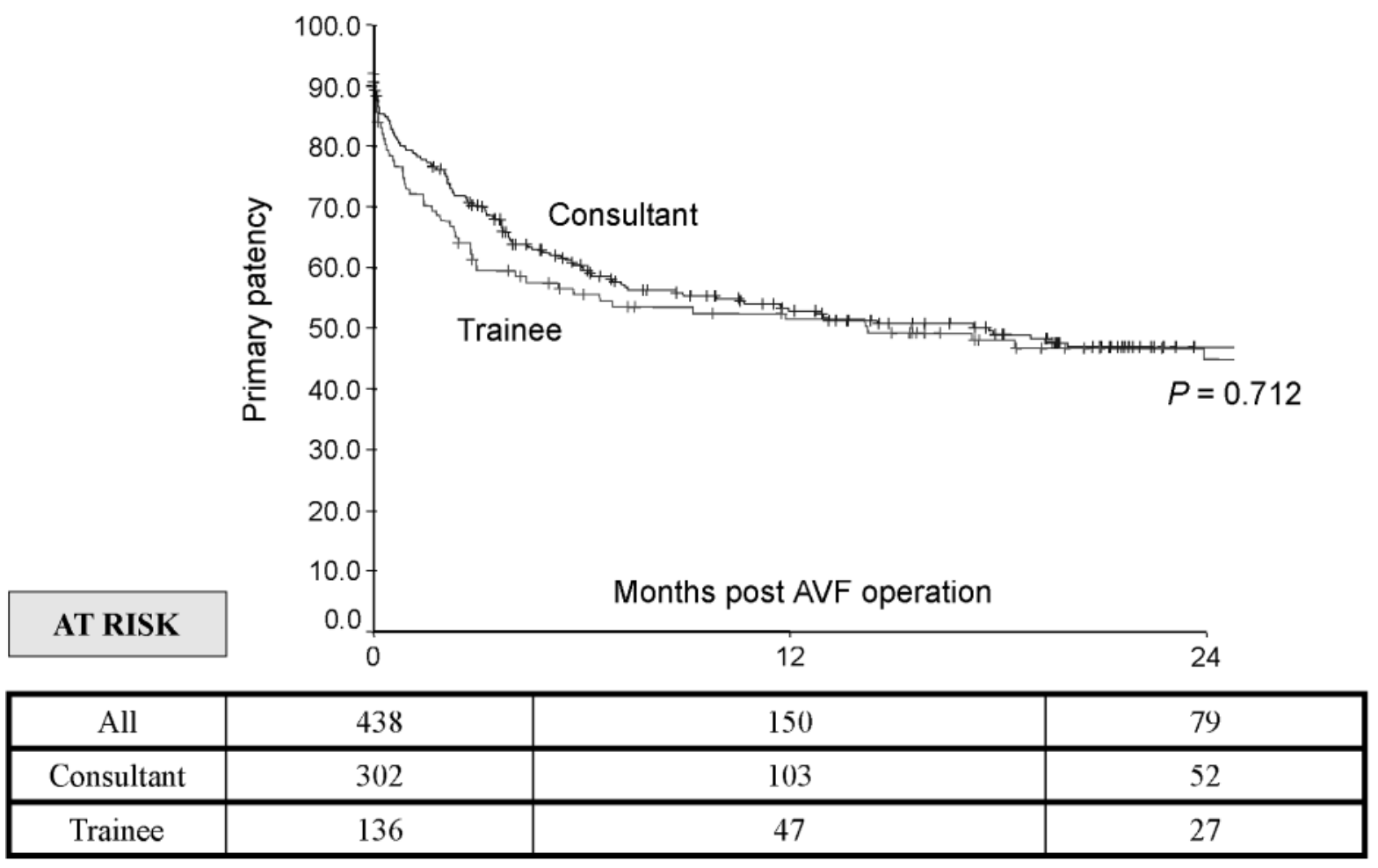

Figure 2 Primary patency.

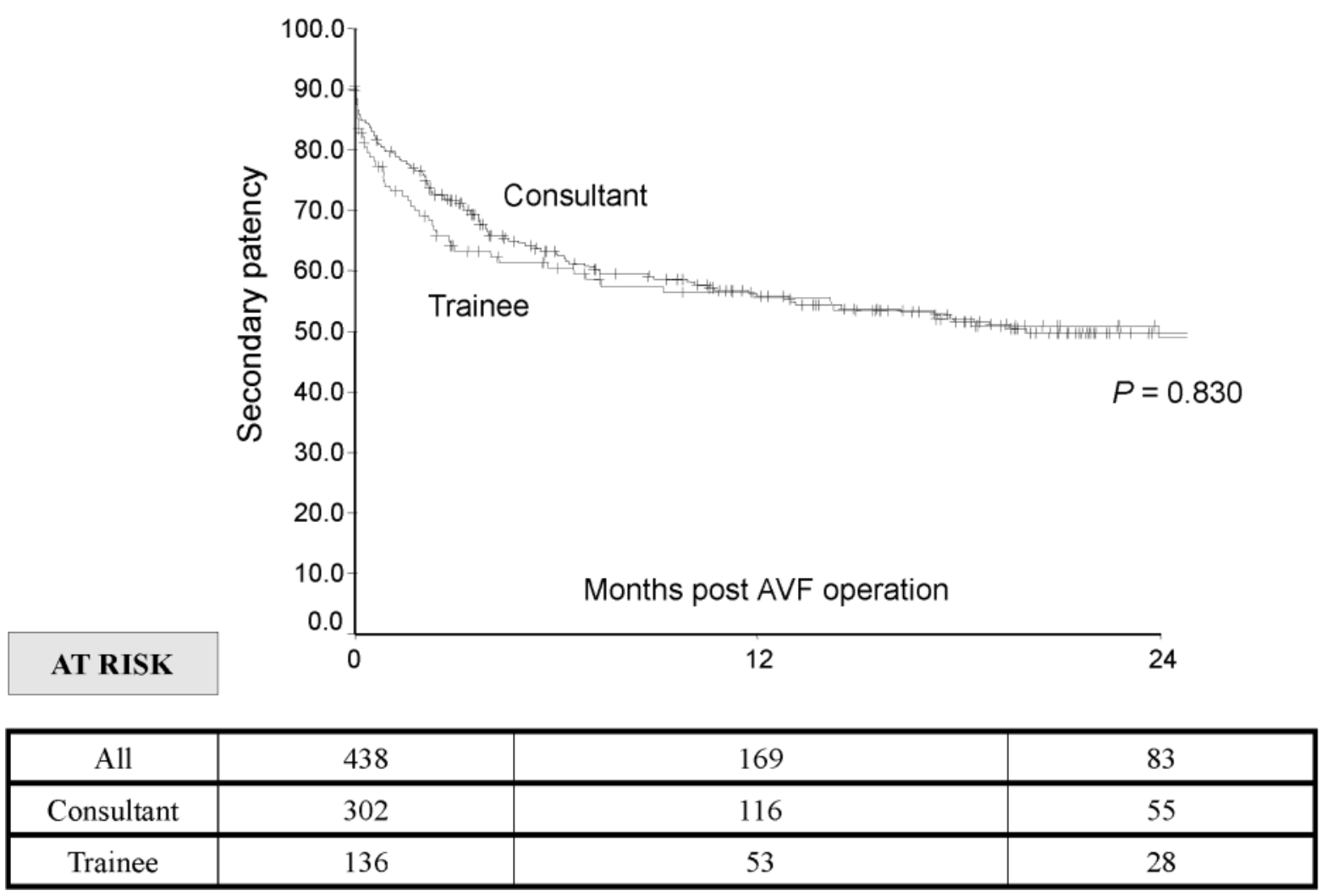

Figure 3 Secondary patency. 


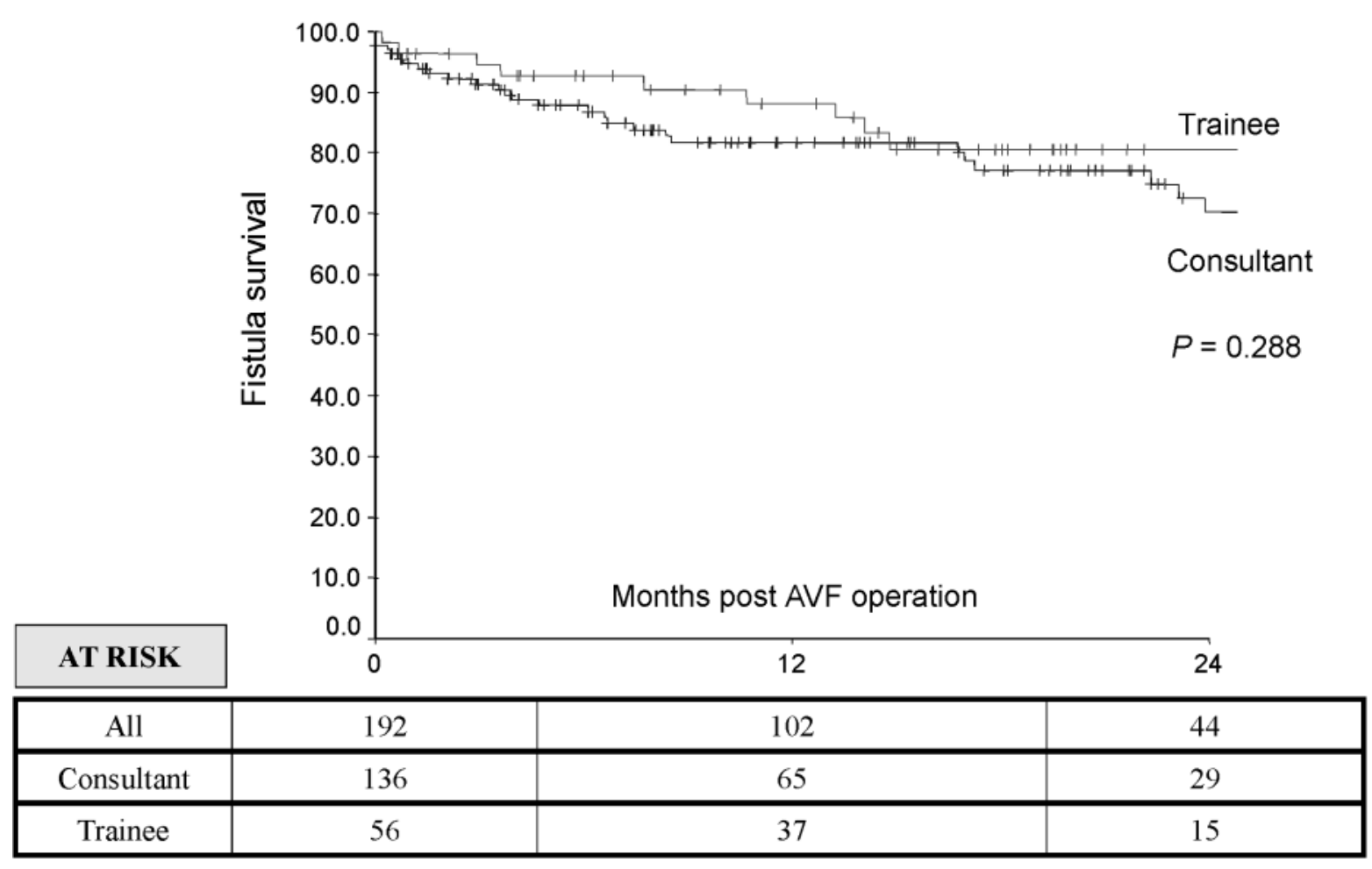

Figure 4 Fistula survival.

illustrated in the survival curve in Figure 2. Secondary functional patency was $55.2 \%$ at 1 year and $48.7 \%$ at 2 years. Similarly, there was no difference between trainees or consultants $(P=0.830)$ as shown in Figure 3.

Of the 204 fistulas used for dialysis, 12 required refashioning prior to use for dialysis; of these 12, 10 were formed by consultants. The remaining 192 patients were considered for assessment of primary fistula survival. Fistula survival at 1 and 2 years was $87.7 \%$ and $78.3 \%$ for trainees and $80.8 \%$ and $71.1 \%$ for consultants $(P=0.288$ log rank), respectively, as shown in the survival curve in Figure 4.

\section{Discussion}

With the reduction in working hours and total training time in both the UK ${ }^{14}$ and Europe, ${ }^{15}$ concern has been raised about the ability of trainees to perform operations without compromising patient care. ${ }^{16}$ Nevertheless, we have demonstrated that trainees have similar rates of patency, successful use and fistula survival compared to consultants in performing primary vascular access surgery for haemodialysis. Although we have not assessed the degree of supervision or pre-operative anatomical features prospectively in this study, we believe that case selection and supervision of trainees is likely to be important to avoid poorer patient outcomes. Given the universally poor outcomes of fistula surgery, the identification of easier cases for a trainee is not straightforward on clinical grounds. As such, the trainee series we present will represent a cross section of difficulty, although in the absence of randomisation, selection bias may have occurred.

The outcomes for supervised surgical trainees in single centres performing lower limb bypass surgery, ${ }^{17}$ carotid endarterectomy, ${ }_{1}^{18}$ cardiac surgery ${ }_{1}^{19}$ upper gastrointestinal surgery, ${ }^{20}$ and colorectal surgery ${ }^{21,22}$ have also been shown to be no different to the supervising consultant specialists. Yet there is evidence from the literature that there is significant intersurgeon variability for patient outcome in various surgical specialties. Positive effects of subspeciality training and increased patient volume on outcomes have been widely reported for outcomes in colorectal $^{23}$ and vascular surgery. ${ }^{24,25}$ It appears that trainees can perform to the standard set by the supervising consultant. The variations in outcomes seen when specialists are compared with non-specialists are not seen with supervised trainees.

The low primary patency rate of $54.1 \%$ at 1 year reflects the tendency of the surgical unit towards placing the most distal access considered clinically feasible, even in an elderly population. Over $70 \%$ of all primary fistulas were performed at the wrist in our series. Both age and female sex are associated with poor outcome for autologous fistulas ${ }^{1,26}$ and in our series the cohort was elderly and with a high proportion of females. 
As the aim of the creation of an AVF is to allow haemodialysis, we have used successful dialysis as the main outcome in our study. As a high proportion of patients do not proceed to haemodialysis due to mortality, transplantation, continuation of peritoneal data or other reasons, we have also considered the effect of trainees on the long-term patency of those fistulas which were successful (i.e. fistula survival).

Where the optimal site for fistula formation has been chosen by the supervising consultant, the trainees' outcome is similar to the consultant, and is over $80 \%$ at 1 year, comparing well with published series of $68-83 \%{ }^{1,4,27}$ Although the presence of a thrill has previously been used as evidence of technical success, clinical criteria are known to predict eventual maturation poorly. ${ }^{13}$ In one study, Won and colleagues found that $93 \%$ of fistulas which failed to mature to be used for dialysis had a thrill present postoperatively. ${ }^{13}$ To avoid presenting potentially misleading data, particularly in the group of patients who never proceeded to haemodialysis, we have not used this subjective clinical sign as a measure of success.

It is acknowledged that trainees must make the most of every opportunity to acquire and improve surgical skills during surgical training. Vascular access surgery provides the ideal opportunity for trainees to perform numerous, ${ }^{12}$ delicate vascular anastomoses in small, yet easily accessible, vessels. Furthermore, such surgery provides the trainee with an opportunity to isolate and handle vessels of the upper limb in an elective setting.

\section{Conclusions}

Surgical trainees do not have a worse outcome than supervising consultants for primary upper limb arteriovenous fistulas. Vascular access surgery can be utilised as a training operation. This finding is of particular importance given the decrease in surgical training time.

\section{References}

1. Pisoni RL, Young EW, Dykstra DM, Greenwood RN, Hecking E, Gillespie $B$ et al. Vascular access use in Europe and the United States: results from the DOPPS. Kidney Int 2002; 61: 305-16.

2. Sidawy AN, Gray R, Besarab A, Henry M, Ascher E, Silva Jr M et al. Recommended standards for reports dealing with arteriovenous hemodialysis accesses. J Vasc Surg 2002; 35: 603-10.

3. Golledge J, Smith CJ, Emery J, Farrington K, Thompson HH. Outcome of primary radiocephalic fistula for haemodialysis. Br J Surg 1999; 86: 211-6.

4. Allon M, Lockhart ME, Lilly RZ, Gallichio MH, Young CJ, Barker J et al. Effect of preoperative sonographic mapping on vascular access outcomes in hemodialysis patients. Kidney Int 2001; 60: 2013-20.

5. Zeebregts C, van den DJ, Bolt A, Franssen C, Verhoeven E, van Schilfgaarde R. Factors predictive of failure of Brescia-Cimino arteriovenous fistulas. Eur J Surg 2002; 168: 29-36.

6. Gibson KD, Gillen DL, Caps MT, Kohler TR, Sherrard DJ, Stehman-Breen $\mathrm{CO}$. Vascular access survival and incidence of revisions: a comparison of prosthetic grafts, simple autogenous fistulas, and venous transposition fistulas from the United States Renal Data System Dialysis Morbidity and Mortality Study. J Vasc Surg 2001; 34: 694-700.

7. Silva Jr MB, Hobson RW, Pappas PJ, Jamil Z, Araki CT, Goldberg MC et al. A strategy for increasing use of autogenous hemodialysis access procedures: impact of preoperative noninvasive evaluation. J Vasc Surg 1998; 27: 302-7.

8. Prischl FC, Kirchgatterer A, Brandstatter E, Wallner M, Baldinger C, Roithinger FX et al. Parameters of prognostic relevance to the patency of vascular access in hemodialysis patients. J Am Soc Nephrol 1995; 6: 1613-8.

9. Huber TS, Ozaki CK, Flynn TC, Lee WA, Berceli SA, Hirneise CM et al. Prospective validation of an algorithm to maximize native arteriovenous fistulae for chronic hemodialysis access. J Vasc Surg 2002; 36: 452-9.

10. Dhingra RK, Young EW, Hulbert-Shearon TE, Leavey SF, Port FK. Type of vascular access and mortality in U.S. hemodialysis patients. Kidney Int 2001; 60: 1443-51.

11. Feldman HI, Kobrin S, Wasserstein A. Hemodialysis vascular access morbidity. J Am Soc Nephrol 1996; 7: 523-35.

12. Weale AR, Lear PA, Mitchell DC. Is day case surgery the key to basic surgical training? Ann R Coll Surg Engl 2002; 84: 426-8.

13. Won T, Jang JW, Lee S, Han JJ, Park YS, Ahn JH. Effects of intraoperative blood flow on the early patency of radiocephalic fistulas. Ann Vasc Surg 2000; 14: 468-72.

14. Crofts TJ, Griffiths JM, Sharma S, Wygrala J, Aitken RJ. Surgical training: an objective assessment of recent changes for a single health board. BMJ 1997; 314: 891-5.

15. Pickersgill T. The European working time directive for doctors in training. BMJ 2001; 323: 1266 .

16. Skidmore FD. Junior surgeons are becoming deskilled as result of Calman proposals. BMJ 1997; 314: 1281.

17. Papp L, Evans SM, Kelman J, Chalmers RT, Murie JA, Bradbury AW. Training in infrainguinal bypass surgery for severe leg ischaemia. $\mathrm{Br} J$ Surg 2001; 88: 82-4

18. Naylor AR, Thompson MM, Varty K, Sayers RD, London NJ, Bell PR. Provision of training in carotid surgery does not compromise patient safety. Br J Surg 1998; 85: 939-42.

19. Goodwin AT, Birdi I, Ramesh TP, Taylor GJ, Nashef SA, Dunning JJ et al. Effect of surgical training on outcome and hospital costs in coronary surgery. Heart 2001; 85: 454-7.

20. Paisley AM, Madhavan KK, Paterson-Brown S, Praseedom RK, Garden OJ. Role of the surgical trainee in upper gastrointestinal resectional surgery. Ann R Coll Surg Engl 1999; 81: 40-5.

21. Praseedom RK, Paisley A, Madhavan KK, Garden OJ, Carter DC, Paterson-Brown S. Supervised surgical trainees can perform pancreatic resections safely. J R Coll Surg Edinb 1999; 44: 16-8.

22. Singh KK, Aitken RJ. Outcome in patients with colorectal cancer managed by surgical trainees. Br J Surg 1999; 86: 1332-6.

23. Tytherleigh $M$, Wheeler J, Birks M, Farouk R. Surgical specialist registrars can safely perform resections for carcinoma of the rectum. Ann R Coll Surg Engl 2002; 84: 389-92.

24. Porter GA, Soskolne CL, Yakimets WW, Newman SC. Surgeon-related factors and outcome in rectal cancer. Ann Surg 1998; 227: 157-67.

25. Feasby TE, Quan H, Ghali WA. Hospital and surgeon determinants of carotid endarterectomy outcomes. Arch Neurol 2002; 59: 1877-81.

26. Kucey DS, Bowyer B, Iron K, Austin P, Anderson G, Tu JV. Determinants of outcome after carotid endarterectomy. J Vasc Surg 1998; 28: 1051-8.

27. Staramos DN, Lazarides MK, Tzilalis VD, Ekonomou CS, Simopoulos CE, Dayantas JN. Patency of autologous and prosthetic arteriovenous fistulas in elderly patients. Eur J Surg 2000; 166: 777-81.

28. Murphy GJ, Saunders R, Metcalfe M, Nicholson ML. Elbow fistulas using autogeneous vein: patency rates and results of revision. Postgrad Med J 2002; 78: 483-6. 